Running Head: Factors related to employment outcomes

\title{
Perspectives of Vocational Rehabilitation Counselors on the Factors Related to Employment Outcomes of Racial and Ethnic Minorities with Disabilities
}

Fabricio E. Balcazar, Ph.D.

Tina Taylor-Ritzler, Ph.D.

University of Illinois at Chicago

Keywords: Vocational Rehabilitation counselors, ethnic minorities, employment

Contact information:

Fabricio E. Balcazar, Ph.D.

Professor \& Director

Center on Capacity Building for Minorities with Disabilities

Department of Disability and Human Development

University of Illinois (M/C 626)

1640 West Roosevelt Rd

Chicago, IL 60608

e-mail: Fabricio@uic.edu

Author note:

This work was funded by the National Institute on Disability and Rehabilitation Research (NIDRR), U.S. Department of Education through a grant to the Center for Capacity Building on Minorities with Disabilities Research at the University of Illinois at Chicago (Grant \# H133A040007). The opinions expressed herein are those of the authors and not necessarily those of NIDRR. 


\begin{abstract}
The current study was conducted to identify effective strategies to promote employment outcomes for individuals with disabilities from diverse cultural backgrounds within the Vocational Rehabilitation (VR) system. Twenty one "excellent or very good" VR counselors, who were nominated by their supervisors, participated in semi-structured qualitative interviews. Participants were 15 females and 6 males, with an average of 17 years of experience in the VR system. The participants identified five themes: (1) an empowerment approach to case management; (2) the importance of developing successful counseling relationships; (3) supports provided to help consumers adjust to or cope with their disability; (4) supports provided to assist individuals with disabilities to develop or refine skills to obtain and maintain employment; and (5) supports provided to assist employers in understanding the benefits of employing individuals with disabilities in general, and accommodating the needs of specific individuals with disabilities. Effective counselors must be flexible, provide additional supports to their clients in specific circumstances and/or challenge them when needed, and more importantly, help clients find ways to overcome and be productive on the job with the necessary accommodations and/or assistive technology.
\end{abstract}


Perspectives of Vocational Rehabilitation Counselors on the Factors Related to Employment

Outcomes of Racial and Ethnic Minorities with Disabilities

The National Council on Disability (2007) suggests that overall employment rates for people with disabilities remain far too low compared with non-disabled individuals. According to the Disability Status Report (2006) prepared by Cornell University which uses data from the 2006 American Community Survey (ACS), only 38\% of working-age people with disabilities (16 to 64 years old) are employed full-time and part-time, compared with $76.9 \%$ of individuals without disabilities. Differences in race and ethnicity widen the gap further: only $29.8 \%$ of African Americans with disabilities and $36 \%$ of Latinos with disabilities are working compared with $40 \%$ of Whites. Zwerling, Whitten, Sprince, Davis, Wallace, Blanck and Heeringa (2002) used the National Health Interview Survey Disability Supplement of 1994 to 1995 to examine the factors associated with employment among Americans with disabilities. They found that persons with disabilities who were more educated and married men were more likely to be working than their counterparts. Moreover, Blacks were less likely to work than Whites. It appears that education, class, and racial differences have a significant impact on the likelihood of employment among people with disabilities.

Several federal laws have been enacted since the 1970s to enhance employment outcomes for people with disabilities. These laws include the 1973 Rehabilitation Act, the 1998 Workforce Investment Act, the 1999 Ticket to Work Incentives Improvement Act, the 2001 New Freedom Initiatives, and the 2004 re-authorization of the Individuals with Disabilities Education Act (IDEA). Many other initiatives aimed at system change also reflect these policy efforts to improve workforce and vocational rehabilitation (VR) options for people with disabilities transitioning into employment, especially for those from traditionally underserved ethnic/racial minority communities (Migliore, 
Mank, Grossi, \& Rogan, 2007).

Under the Rehabilitation Act of 1973, federal grants are awarded to assist states with the operation of comprehensive vocational rehabilitation programs. The goal of these programs is to provide VR services to eligible individuals with disabilities that contribute to gainful employment. To be eligible for VR services, an individual must have a physical or mental impairment that is a substantial impediment to employment; be able to benefit in terms of employment from VR services; and require VR services to prepare for, enter, engage in, or retain gainful employment (Wheaton, Wilson, \& Brown, 1996). To effectively prepare people for employment, VR services are supposed to be provided in a manner that is consistent with clients' strengths, resources, priorities, concerns, abilities, and capabilities.

Vocational rehabilitation (VR) is the component of the rehabilitation process that assists people with disabilities in the adjustment or readjustment to work (Sampson, McMahon, and Burkhead, 1985). Given its prominence, there is a need to understand the utilization of VR services by minorities with disabilities. With its goal of equalizing the opportunities of people with disabilities (Atkins \& Wright, 1980), VR has the potential to be a tremendous resource for people with disabilities who want to work. Such services may be especially critical for minorities with disabilities who tend to have higher rates of disability and lower rates of employment.

From a social work perspective, Patchner (2005) pointed out that social work professionals have historically approached disability from a medical perspective, where the definition of the problem was the physical or behavioral impairment of the individual, and the emphasis of the interventions was curative in nature. Patchner also suggest that the social service/rehabilitation perspective in social work (as described in Condeluci's 1995 literature review) viewed individuals with disabilities as having a lack of adaptability to their surrounding 
environment, which resulted in little decision-making and control of the individuals being helped. The emergence of the independent living movement, which promoted the selfdetermination of people with disabilities, civil rights legislation like the Americans with Disabilities Act, which promoted equal access and opportunities, and the social model of disability, which emphasizes the role of the social and physical environment as key factors that limit full participation in society, highlights a sea of change in the way people with disabilities are treated and/or served by rehabilitation and social work professionals.

Occupational social workers can play an important role in supporting employees with disabilities in assessing work abilities, seeking accommodations and protection from discrimination in the work place, developing plans for securing income and health insurance, and helping maintain family functioning and self-esteem (Mudrick, 1991). Mudrick noted that social workers can also provide a mixture of counseling to individuals and families, provide information about public and private social welfare and insurance benefits, and mediate between employees and employers. Mudrick concludes that "occupational social workers are uniquely qualified to provide assistance to employees and employers in the area of disability because the issues they face reflect a mix of individual qualities, public and social policy, and workplace necessity" (p. 495).

\section{Purpose of the Present Study}

The purpose of the present study was to explore and better understand the supports provided by VR counselors to non-White individuals with various disabilities seeking employment. Given the high rates of disparities in access to services and positive employment outcomes for ethnic minorities with disabilities, the current study sought successful cases that included non-White consumers with disabilities. An employment outcome according to the 
Rehabilitation Services Administration (2008) is defined as entering or retaining full-time or, if appropriate, part-time competitive employment, supported employment, or any other type of employment in an integrated setting for a minimum of 90 consecutive working days. The study also seeks to contribute a narrative of success to the literature on the employment of people of color with disabilities.

\section{METHOD}

\section{Participants}

Twenty one "excellent or very good" vocational rehabilitation (VR) counselors from a large Midwestern state were nominated by their supervisors to participate. These were individuals who had demonstrated consistent rates of positive rehabilitation outcomes over the years in their respective offices as perceived by their supervisors. Participants worked in VR

offices throughout the state. As such, they worked in rural, suburban, urban, and medium sized communities. Demographically, the counselors were representative of those working within the state VR system. Sixteen were White, four African American, and one Native American. In addition, two counselors disclosed that they had visible disabilities. Fifteen were female and six male, with an average of 17 years experience in the VR system $(\mathrm{SD}=9.29$; Range=6-40).

\section{Instrument}

The researchers developed a semi-structured interview protocol which included 24 questions, along with probes. Areas of questions included: (1) understanding the community where the counselor worked, including its geography, industry and socio-economic characteristics; (2) understanding the counselor's caseload, including size, racial/ethnic, age, disability, and socio-economic characteristics; (3) understanding a successful case of a nonWhite consumer, in particular the supports provided to the consumer by the counselor; and (4) 
understanding who the counselor is, including the counselor's race/ethnicity, number of years of experience as a VR counselor, and greatest satisfaction in his or her work.

The interviews were conducted over the phone, given the geographic dispersion of the counselors. They were audio-recorded and lasted an average of 31.50 minutes (Range: 24-48 minutes).

Procedures

Data collection procedure. The Director of the state VR agency agreed to have counselors participate, according to the procedures described here. First, IRB approval was obtained from the University of Illinois. Then, a recruitment letter was sent from the state Director to all VR supervisors asking them to invite "an excellent or very good" counselor who had been employed by the state for at least five years to participate in the study. If interested, counselors were asked to contact the researchers to discuss the study and schedule a time to participate via telephone. When counselors called, the researchers explained the procedures, and risks and benefits of participating in the interview. A total of 22 counselors called and expressed their interest to participate in the study. A consent form was emailed to them and they were asked to read, sign and fax the completed consent form back to the researchers. Once the completed consent form had been received, the researchers conducted the phone interview. Only one counselor changed her mind and refused to participate.

Data analysis procedure. As noted, all interviews were audio recorded and transcribed verbatim. The transcripts were subjected to commonly accepted qualitative data analytic procedures (Miles \& Huberman, 1994; Strauss \& Corbin, 1990). Specifically, Vaughn, Schumm, and Sinagub (1996) describe the coding process as having five main steps: (1) identify the big ideas in the data by reading the transcripts; (2) code or unitize the data by identifying the 
smallest amount of information in each transcript that was informative; (3) categorize the units of information that were identified in the second step; (4) discuss the coding process with another analyst to determine whether the codes that were developed were appropriately applied to the data; and (5) group the codes into themes for reporting.

\section{RESULTS}

The current study aimed to identify and understand the supports provided by VR counselors to non-White consumers with disabilities seeking to attain successful employment outcomes. Participants described 21 successful cases involving non-White consumers: 14 consumers were African American, six Latino, and one Latino and Native American. Participants reported that over half of the consumers were living well below the poverty line; in one case the consumer was homeless when services began. In the remaining cases, the consumers' family income was less than $\$ 40,000$. Consumers were an average of 33 years old (Range: 18 to 47 years). Eleven consumers were male and 10 were female. A wide range of disabilities were represented, including cognitive (e.g., mild mental retardation, learning disability, autism), physical (e.g., spinal cord injury, stroke), psychiatric (e.g., mental illness, drug addiction), and sensory (e.g., blindness).

The qualitative analysis of the interview transcripts revealed five primary themes which are reported below: (1) an empowerment approach to case management; (2) the importance of establishing a successful counseling relationships; (3) supports provided to help consumers adjust to or cope with their disability; (4) supports provided to assist individuals with disabilities to develop or refine skills and to obtain and maintain employment; and (5) supports provided to assist employers in understanding the benefits of employing individuals with disabilities in 
general, and accommodating the needs of specific individuals with disabilities. Figure 1 describes the identified themes and how they relate to employment outcomes.

Insert Figure 1 about here

\section{An Empowerment Approach to Case Management}

The most significant contributor to the success of the consumers whose stories were reported by the VR counselors was related to the philosophy of practice described by the counselors. This general framework appears to impact all other aspects of the counseling process. They stated that an empowerment approach was central to their reasons for being counselors and critical to their daily purpose in their work. An empowerment approach and the goals of empowering consumers to be in control of their lives and to maximize their independence and self esteem were clearly articulated. This approach was also explicitly contrasted with expectations that the goal of the rehabilitation process is for consumers to earn high incomes.

...that doesn't mean that [consumers] have to be working making a million dollars. It means that they are doing what makes them the best person they can be, and what they're enjoying it. Paying their own bills, saving for things they want. You know just such self esteem that comes from that... And to learn about themselves and to be able to maneuver the world... Advocating for themselves, and finding those experiences that enrich their lives through employment and being independent. (VR02)

The empowerment perspective reflects two dimensions of the process. On the one hand, the counselors themselves felt empowered to address their cases as they deemed necessary; 
sometimes this involved being flexible with the rules of the agency in order to address the pressing needs of their clients in an effective way, as will be explained in the other sections. On the other hand, the counselors noted the importance of empowering their clients, through constant encouragement and support, modeling and teaching advocacy skills, and also reinforcing self-esteem. This process was evident in their efforts to support clients in their process of career development by helping them learn how systems work and how to advocate for themselves within employment-related systems.

Those paths [to getting services within the VR system] had to be smoothed for him initially. I smoothed some of them. His uncle did that. He's learning though how to do that on his own ... if he needs something and he's not quite sure how to do it. He will immediately contact me through email. (VR02)

\section{Establishing Successful Counseling Relationships}

The participants were clear in reporting that the goal of maximizing consumers' independence was contingent on developing a successful counseling relationship. Participants identified three strategies for building positive counseling relationships: (1) establishing rapport, (2) providing person-centered support, and (3) instilling motivation. These strategies were also a reflection of the counselors' experience and their personal orientation to the counseling relationship. Regarding rapport, one of the counselors said,

I think the most important and crucial part of the counseling process is really listening to the client and building a really strong rapport ...(VR16)

This rapport was seen as critical to understanding the consumers' goals for the rehabilitation process and also as central to a person-centered approach to therapy, as shown below. 
Participants reported that a significant aspect of the rehabilitation process is working to support the goals and wishes of the person with a disability, which is a central tenant of the disability rights movement. Counselors also reported adjusting the method and sometimes the policies regarding service provision to fit with the needs of the consumer. For example, I also met with [the consumer] frequently. Some appointments were scheduled. Others were not scheduled which was kind of like an open-door policy for [the consumer]. [The consumer] knew she could come in if she needed to discuss with me something related to her achieving her goal like an interview she may have went on, or change offeelings or thoughts she had about her vocational goals. So I left the door open for [the consumer] to come in as she pleases, and we did have also scheduled appointments. I ... used like a person-centered approach with her. (VR10)

This willingness to be flexible can be critical in allowing consumers to feel welcomed and to develop a sense that the counselor cares about their situation. The goal of person-centered support was contrasted with the challenges of following procedures and meeting significant documentation requirements.

I think ... sometimes we get so caught up in just making sure all the forms are signed and the pieces are in the file-- but we forget and lose track of the client and what they're here for. (VR16)

Another aspect of a successful counseling relationship was keeping the consumer motivated to continue to work on his or her goals. This strategy was relevant because minority individuals with disabilities often face many barriers to attaining and maintaining employmentsuch as limited educational and employment experiences, severe disability, poverty and limited access to transportation or childcare services. 
[the consumer] sometimes gave up easily or wanted to throw in the towel... but ... we persevered with [the consumer] and had discussions about the services that could be beneficial to [the consumer] so that he could be most successful. (VR11)

\section{Supports Provided to Help Consumers Adjust to or Cope with their Disability}

A significant role for VR counselors was working with consumers with disabilities to help them understand their strengths and limitations and identify their interests and vocational goals. There were three strategies that were used to achieve this goal: (1) Conducting vocational assessments; (2) helping consumers understand their disability; and (3) challenging consumers to face their problems.

The process of identifying strengths and limitations, for many consumers, involved participating in a formal vocational assessment. After the assessment had been completed, counselors used the information obtained to help consumers take stock. One counselor pointed out:

I think clients should really know what their strengths and weaknesses are. They should have a good self understanding, because out of that comes, you know, a better matching of goals and jobs when they go to pursue them-- as well as the ability to communicate to the employer, "This is my limitation; this is what I need from you to help me overcome this limitation and reduce this limitation." Without that self-awareness, then you know, you get into those cyclical type of-- you're in a job, you lose the job, you're in a job, you lose the job. (VR16)

Counselors, together with their consumers, used the results of formal vocational assessments to inform the development of vocational plans and to identify careers of interest that matched the consumers' abilities and interests. For example, 
Then we ... put [the consumer] in a program that also pops up jobs that those interests apply to. So that's what we were looking for, for [the consumer] to be able to have an idea of some of jobs that were available with those interests and those talents that [the consumer] showed. (VR02)

A significant role for counselors was assisting consumers in adjusting to and accepting their disability. This was particularly true for consumers who had recently acquired a disability or who had recently experienced a loss of function. In these cases, counselors reported working with consumers to help them set realistic goals related to employment, particularly, goals that took their health limitations into account.

Another important role for counselors involved working with consumers to help them understand and define appropriate behavior in the workplace; skills that they did not have because of their limited employment experience. In one example, a counselor described her work with a young man with autism.

I would say that the greatest challenge is the ... social struggle with the autism ... we would talk about, you know, situations would occur and then he would just sort of pop into my office ... So we would talk about the situation how it went, what he said and what he might have said differently to accomplish what he wanted. So we would do a little role playing. (VR02)

In some cases, confrontations were necessary in order to increase the consumer awareness of the consequences of his/her behaviors. In one example, a counselor reported confronting a consumer about his alcohol abuse in order to get him help, ... confronting [the consumer] about his problem, explaining to him... what could be some of the consequences of his behavior, like losing his job. He had a really nasty scar 
on his face where he was-- had been intoxicated and he fell down and hurt himself. So part of the counseling sessions included ... confrontation, talking about consequences that could occur because of his behavior. (VR09)

\section{Supporting Individuals to Obtain and Maintain Employment}

A central role of VR counselors is to support people with disabilities in the process of career development. Consistent with best practices in this area, participants reported supporting consumers with disabilities in several aspects of the job development and placement process: (1) job development skills; (2) job search supports; and (3) providing on-the job supports as needed. VR counselors described helping their consumers with disabilities to develop job skills, including searching for jobs that matched their interests and abilities in their community. In some cases, this assistance was provided in one-on-one counseling sessions. In other cases, counselors had developed "Job Clubs" where several consumers came together to discuss job leads and other aspects of job development on a weekly basis. For example,

Well, our job club, we have ongoing and it meets for I want to say, six consecutive weeks. We have different sessions. And the customers come... they go over job skills, job readiness, training, and they end up being a cohesive group and a support for each other. So I guess that was another support for her, her job club. That was a big support for her. Once she started the job club, it really was that, a club. She did find support from that. So they just give them skills and knowledge that they can use to help them obtain employment...(VR10)

Another job development skill area is helping consumers prepare for job interviews. In some cases, counselors practiced mock interviews with the consumers; in others, they engaged employers in a mock interview process. 
I ... worked with him on interviewing skills, interviewing techniques, on what to say, how to handle the fact that he hadn't worked in an extremely long period of time ... He also participated in mock interviewing where we would call employers and have ... them to actually interview him and give us feedback as to how well he performed in the mock interview. (VR09)

VR counselors also described providing consumers with other types of support related to obtaining employment. One counselor described working with a consumer to complete the final steps of a long process of working toward employment as an attorney. In this case, the Bar exam application was not accessible to the consumer with low vision in its computer version, so the counselor completed it for her with her guidance. After the application was approved, the consumer took the Bar exam in an accessible format, passed the exam and was able to secure employment as an attorney. But without assistance in completing the examination application, this process would have stalled.

In another case, a VR counselor helped a consumer access and submit paperwork to explain a prior incarceration in order to access a job.

Obviously he was going to have a hard time getting a job because of his felony background. It was all drug related. ... He really had nothing. He didn't have a family, and he wasn't allowed disability money, and we would have to even help with the bus pass just to get here. Then we ended up helping him [to get a job]. ... but in order to do this, we had to help him get his court records ... He had to document that he was not convicted or incarcerated for any crime against another person. They will take you for drugs but not battery or assault or anything like that. Since this had all happened out of state we had to pay for the background checks and this and that. It was a long process, 
but he did get [the job] and has been there successfully and remains there at about $\$ 13$ dollars an hour. (VR24)

Once consumers had secured a job, VR counselors worked with them to provide other supports that were necessary for on-the-job success. Specific examples of employment-related supports were many. For example, VR counselors worked with consumers to ensure that they had uniforms or other appropriate clothing that they needed for their job:

We bought his uniform and black pants, steel toed shoes, white shirts to get him started with the understanding that whatever he needed in the future he would pay for himself and he was fine with that. (VR24)

Another example of an employment-related support was helping consumers access needed transportation to work. In some cases, transportation assistance included helping consumers to learn bus routes or other ways of getting themselves to work. In other cases, transportation assistance included providing discounted or fully funded bus passes to consumers. One of the challenges we had was the issue of transportation when he was actually looking for work. He had very limited income, so ...he signed up to get the discounted bus pass, and then we actually purchased a bus pass for him. We purchased a bus pass for him to look for work, and then we purchased a bus pass for him when he found his job, until he got his first paycheck, so he would be able to get to work. (VR09) Counselors also described cases in which consumers wanted promotions at their job sites that required additional training or education.

Well, we both discussed the path in which it would take to get his training and ultimately his promotion, so he had to identify a school, identify the certificate courses, apply for the courses and participate in the courses. (VR11) 


\section{Assisting Employers to Understand Disability}

Finally, VR counselors discussed working to educate employers about disability issues and working to help arrange for accommodations for particular consumers with disabilities. This process included building relationships with employers, offering trainings and consultations as requested, educating employers about specific individuals with disabilities (see example bellow), or about their responsibilities under the Americans with Disabilities Act.

I worked with a few other people on a team, and advocated with an employer to help them understand the disability in his particular situation-certainly with his permission [the consumer's]; but advocated so that they could understand the process of what we were doing with him and the expected outcome and benefit that they would experience in the long run by hiring him. (VR01)

In addition, counselors also gave assistance to employers in the process of providing adaptive technology to individuals who may need to perform job functions. One counselor described the process as follows:

I made referrals for her to other service providers, helped her with arranging for the purchase of assisted technology... [and] purchasing it for her. (VR13)

\section{DISCUSSION}

This qualitative study intended to provide a better understanding of the supports offered by VR counselors to non-White consumers with disabilities in the process of promoting attainment of their employment outcomes. The results from this study reveal important components of the counselor's performance that seem in some instances obvious for a counseling relationship, but that are often lost in the bureaucratic maze of state agency services, form-filing and inflexible rules and regulations. As these narratives reveal, effective counselors 
are flexible; have an open door policy (not always requiring clients to set appointments in advance; understand the need to provide additional supports to their clients in specific circumstances and/or challenge them when needed; know the strengths and challenges of their clients; and help their clients recognize their limitations and more importantly, finding ways to overcome barriers and be productive on the job with the necessary accommodations and/or assistive technology. What is critical, is that the counseling relationship can be framed in the context of consumer empowerment, in which the consumer is encouraged and supported to take more responsibility for his/her own future and most importantly, taking a proactive role in completing the necessary tasks required to attain their rehabilitation goals.

In part as a response to the historical oppression of individuals with disabilities, Beaulaurier and Taylor (2001) propose a conceptual framework for social work practice that: (1) maximizes client's involvement in exploring an expanded range of options an choices; (2) prepares clients to be more effective in dealing with professionals, bureaucrats and agencies that often do not understand nor appreciate their need for self-determination; and (3) at the organizing level, mobilizes and helps to empower groups of people with disabilities to consider policy and program alternatives that can improve their situation. These recommendations are consistent with the findings from this study and should enhance the effectiveness of social workers supporting individuals with disabilities.

In her introduction to a special issue on social work practice with people with disabilities, Galambos (2004) points out current challenges in the areas of professional practice, education and research. She mentions that in the practice area, social workers have still much to learn about working with people with disabilities, emphasizing the need to move beyond limitations and stereotypes while concentrating on client's strengths and incorporating an empowerment 
perspective (see Beaulaurier \& Taylkor, 2001). With regards to education, Galambos mentions the importance of strengthening content related to disabilities in the social work curriculum of schools and professional programs. This can increase students' understanding of the issues and concerns of people with disabilities. She also emphasizes the importance of conducting more research on ability-related issues and emerging paradigms in the disability field (Pardeck, 2002). The National Association of Social Workers [NASW](2009) developed a policy statement that acknowledges that the presence of a disability is a characteristic, not an individual's sole identity, and that people with disabilities may be handicapped by environmental, or individual, or societal attitudes, and not solely by their impairment. In addition, the NASW supports and is willing to take action with people who have disabilities in advocating for their rights including the freedom to live independently, to enjoy the rights of full societal membership, to exercise selfdetermination, and to have full participation in issues related to education, housing, transportation, work, health care, social services, and other public accommodations. NASW also recognizes that discrimination based on disability is a global problem and is therefore working to positively influence perceptions and achieve equity for all.

In this study, counselors who are aware of the importance of empowering their clients so they increase their independence, self-esteem and self-reliance had a better chance of breaking the dependency that many clients acquire when interacting with paternalistic service delivery systems. In the case of clients with disabilities, this empowerment approach is consistent with the values of the independent living movement, a movement that many consumers value and appreciate. However, many immigrants have a difficult time understanding the meaning of empowerment - particularly those who are poor and/or have a history of oppression and marginalization. In addition, many individuals with severe disabilities are often overprotected by 
family members and/or service providers which also limit their sense of independence. In these cases, the counselors have to take extra time to help clients learn how to become empowered, advocate for their rights and request necessary accommodations.

The success of every counseling relationship also requires establishing good rapport and effective communication (Lewis \& Shamburger, in press). In the case of individuals with disabilities, this may require sing language translators or adaptive technology. It becomes important that the clients learn about the environmental adaptations and modifications that would allow them to be effective and productive in their jobs. In the case of acquired disabilities, the client may not be aware of the existing devices and technology available to support him/her or may lack the resources to afford the equipment. This is one of the roles that VR services can provide to help clients adjust to their disability and become productive.

Offering supports to assist individuals with disabilities develop or refine skills to obtain and maintain employment is also critical. The participating counselors offered both individual (role playing) and group supports (job clubs) to help their clients in this process. It is also important to keep the client motivated in the challenging and often frustrating process of seeking employment. This is more difficult for minority individuals with disabilities who often encounter double discrimination (Wilson \& Senices, in press). This is one of the reasons why effective counselors assist employers in understanding the benefits of employing individuals with disabilities. It is a role that requires constant engagement with community members, educational efforts to increase community awareness, as well as advocacy. Although counselors in this study were encouraged to focus on clients of color, we cannot be sure that all of the examples provided actually took place with such clients. This was an exploratory study and additional research is 
needed to examine these strategies with a larger sample and perhaps considering the different demands that particular industries or occupations pose to the task of the counselors. 


\section{References}

Atkins, B. J., \& Wright, G. N. (1980). Three views: Vocational rehabilitation of Blacks: The statement. Journal of Rehabilitation, 46(2), 42-46.

Beaulaurier, R. L. \& Taylor, S. H. (2001). Social work practice with people with disabilities in the era of disability rights. Social Work in Health Care, 32(4), 67-91.

Cameto, R., Marder, C., Wagner, M., \& Cardoso D. (2003). Youth Employment. NLTS2 Data Brief, Reports from the National Longitudinal Transition Study, Vol. 2, Issue 2. Retrieved April 4, 2009 from: http://www.ncset.org/publications/viewdesc.asp?id=1310

Condeluci, A (1995). Interdependence: The route to community ( $2^{\text {nd }}$ Ed.). Winter Park, FL: GR Press, Inc.

Disability Status Report (2006). Retrieved April 3, 2009 from: http://www.ilr.cornell.edu/edi/disabilitystatistics/

Galambos, C.M. (2004). Social work practice with people with disabilities: Are we doing enough? Health \& Social Work, 29(3), 163-165.

Lewis, A. \& Shamburger, A. (in press). A three dimensional model for multicultural rehabilitation counseling. In (Balcazar, Suarez-Balcazar, Taylor-Ritzler \& Keys, Eds.) Race, Culture and Disability: Rehabilitation Science and Practice. Jones \& Bartlett: Boston, MA.

Migliore, A., Mank, D., Grossi, T., \& Rogan, P. (2007). Integrated employment or sheltered workshops: Preferences of adults with intellectual disabilities, their families, and staff. Journal of Vocational Rehabilitation, 26, 5-19.

Miles, M. B. \& Huberman, A. M. (1994). Qualitative data analysis. Thousand Oaks, CA: Sage Publications. 
Mudrick, N. R. (1991). An underdeveloped role for occupational social work: Facilitating the employment of people with disabilities. Social Work, 36(6), 490-495.

National Association of Social Workers (2009). People with disabilities. Social Work Speaks Abstracts. Retrieved March 27, 2009 from http://www.naswdc.org/resources/abstracts/abstracts/PeopleWithDisabilities.asp

National Council on Disability (2007). National Council on Disability Says Increase Employment Opportunities for People with Disabilities. Retrieved April 3, 2009 from: http://www.ncd.gov/newsroom/news/2007/r07-544.htm

Pardeck, J. (2002). A critical analysis of the social work literature on disabilities. Journal of Social Work in Disabilities \& Rehabilitation, 1(2), 1-5.

Patchner, L. S. (2005). Social work practice and people with disabilities: Our future serves. Advances in Social Work, 6(1), 109-120.

Rehabilitation Services Administration [RSA]. (2008). Evaluation standards and performance indicators for the Vocational Rehabilitation Program. Retrieved February 3, 2009 from http://www.ed.gov/legislation/FedRegister/finrule/2000-2/060500b.html.

Sampson, J. P., McMahon, B., \& Burkhead, E. J. (1985). Using computers for career exploration and decision-making in vocational rehabilitation. Rehabilitation Counseling Bulleting, $28,242-262$.

Strauss, A., \& Corbin, J. (1990). Basics of qualitative research: Grounded theory procedures and techniques. Newbury Park: CA: Sage Publications.

Vaughn, S., Schumm, J. S., \& Sinagub, J. (1996). Focus group interviews in education and psychology. Thousand Oaks, CA: Sage. 
Wheaton, J. E., Wilson, K.B. \& Brown, S. M. (1996). The relationship between vocational rehabilitation services and the consumer's race, gender, and closure status. Rehabilitation Counseling Bulletin, 40, 116-133.

Wilson, K. \& Senices, J. (in press). Access to Vocational Rehabilitation Services for Black Latinos with Disabilities: Colorism in the 21st Century. In (Balcazar, Suarez-Balcazar, Taylor-Ritzler \& Keys, Eds.) Race, Culture and Disability: Rehabilitation Science and Practice. Jones \& Bartlett: Boston, MA.

Zwerling, C., Whitten, P.S., Sprince, N.L., Davis, C.S., Wallace, R.B., Blanck, P.D., \& Heeringa, S.G. (2002). Workforce participation by persons with disabilities: the National Health Interview Survey Disability Supplement, 1994 to 1995. Journal of Occupational and Environmental Medicine, 44 (4). 358-364. 
Figure 1: Factors Related to Employment Outcomes

\section{Of Racial and Ethnic Minorities with Disabilities}

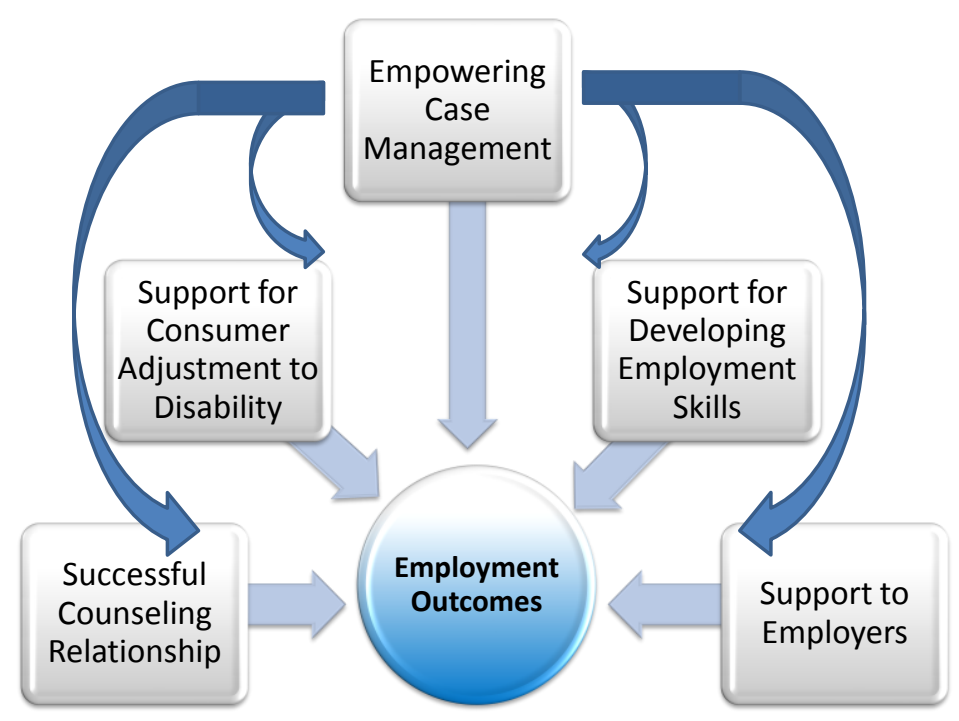

